\title{
Improving the Availability of Emergency Power Supply in Nuclear Power Plant
}

\author{
M. El-Shibini, M. El-Marsafawy and M. EssawY* \\ Electrical Eng. Department, Faculty of Engineering, Cairo University \\ ${ }^{*}$ Nuclear Regulatory and Safety Center, \\ Atomic Energy Authority, Cairo, Egypt
}

\begin{abstract}
The improvement of emergency power supply availability in nuclear power plant (NPP) was studied by utilizing the stored energy in the turbogenerator system, during its run-down to supply the safety loads during the power-off period following the loss of offsite power, due to a nuclear reactor fault, which requires immediate reactor shut down and as a consequence turbine/generator shut down. A computer model to simulate the electric power system in the NPP has been developed.
\end{abstract}

The dynamic response of the system was analyzed and results have shown that the stored energy could successfully supply the safety loads of the NPP for a period of about 20 seconds before diesel generator start-up, without considerable deviation from their rated values. This in turn will improve the availability of the emergency power supply.

The information provided in this paper should be of great interest to electric utility planners and operators and turbine/generator manufacturers.

\section{Introduction}

Nuclear industry has its special standards and regulations, which are changeable with time in compliance with the improvements made in system design due to the found out defects in them. Most of these defects are discovered during accident experiences, which are hard but may be useful. It can be mentioned of these accidents, the Three Mile Island (TMI) accident that took place in USA (March, 1979), and Chernobyl accident that took place in USSR (April, 1986). 
An experiment was conducted at Chernobyl nuclear power plant to investigate the possibility of utilizing the mechanical energy of the rotor in a turbogenerator cut off from the steam supply to sustain the unit's own power requirements during a power failure. However, both inadequate performance of the plant staff during the execution of the experiment and their violation of some safety regulations and obligations had led to the known accident. ${ }^{[1]}$.

Before the end of this century, the first nuclear power station, to be located at ElDabaa on the north west coast near Alexandria, Egypt, is expected to be in operation and supplying the Egyptian Unified Power System.

Both the great interest shown by the Egyptian government in installing nuclear power stations in Egypt and the Chernobyl accident have provided the incentive to conduct research studies in the area of nuclear power of which the contents of this paper form a part.

This paper is directed towards studying the improvement of emergency power supply availability in a NPP. A certain strategy of electric power system operation is proposed for achieving system availability improvement. It is intended through this strategy of system operation to utilize the stored energy in the turbogenerator system during its run-down, to supply the safety loads, during the power-off period after the loss of offsite power, and before the diesel generator start-up. This operating strategy, as mentioned before, was tried on Chernobyl plant, but due to some faults in implementing the program of the experiment, it led to the accident.

A computer model to simulate and analyze the dynamics of the power system has been developed.

An investigation of how long the stored energy could successfully supply the safety loads without deviation from their rated values is presented. It is shown from the results in this paper that the use of this additional supply to the emergency power supply system will increase its availability. Increasing system availability improves the safety of the NPP ${ }^{[2,3]}$, and decreases the probability of loss of power supplied to safety loads, specially during accident conditions.

Included in this paper are mathematical model, solution technique, results and its discussions, and a proposed operating strategy for the NPP.

\section{Mathematical Model}

The developed model has additional capabilities over previous models ${ }^{[4,5]}$ to suit the suggested strategy of system operation, which includes two very distinct operating situations. The first situation is the operation of the nuclear unit with the utility grid, which is a very rigid and normal type of operation. The second situation is the isolated operation of the nuclear unit with its auxiliaries, which is a very loose and abnormal type of operation.

To achieve the required capabilities, system representation is not unified into one form, as the case in previous models, but is divided into separate linked parts as 
shown in Fig. 1. The idea behind this representation is to achieve the ability of intervention at different parts in the system to make disturbances. It also gives the ability of action direction control, state recalculation, and resulted disturbance interchange between different system parts.

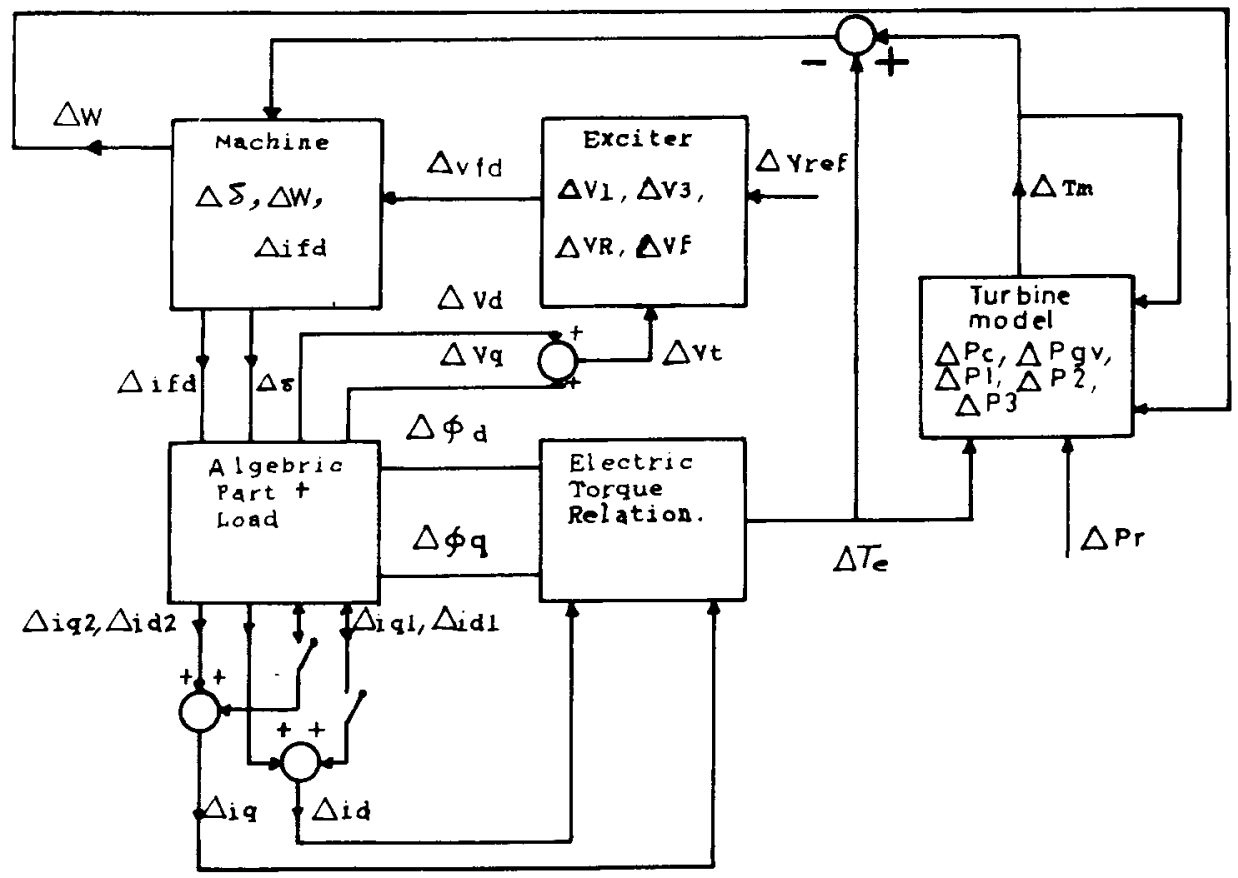

FIG. 1. System main parts and flow of variables interaction.

The first capability of the model is the simulation of the system major disturbances such as turbine shut down and transmission line switching. Analysis of large disturbances has been presented in Ref. [6]. But this has been handled differently in this paper, through updating the operating point after each time step, and using a certain disturbance distribution function that distributes the major disturbance on a certain number of time steps, taking into account the numerical stability limits of the model and the physical characteristics of the disturbance itself.

The mathematical equations of every part in the model are written in the state space form as follows :

$$
\begin{aligned}
& {\left[x^{\cdot}\right]=[A][x]+[B][u]+[\Gamma][P]+[\epsilon][h]} \\
& {[y]=[C][x]}
\end{aligned}
$$

where :

$$
\begin{aligned}
& {[x]: \text { state space vector }} \\
& {[u]: \text { control vector }}
\end{aligned}
$$


$[P]$ : disturbance vector

[ $h$ ] : linking vector

[ $A$ ] : system matrix

[ $B$ ] : control input distribution matrix

$[\Gamma]$ : disturbance distribution matrix

[€] : linking variables distribution matrix

[C] : output matrix

$[y]$ : output vector.

The above state space representation is the same as the conventional one except that we have an additional linking part, represented by the term $[\epsilon][h]$, which links the different parts of the divided system. As shown in Fig. 1, a state variable for a certain part may be converted to be a control variable, disturbance variable, or a linking variable in another part. For example, change in speed $\Delta W$ is a state variable in the machine part and a control variable in the turbine part, $\Delta P 1, \Delta P 2$, and $\Delta P 3$ are state variables in the turbine part, that are combined to give $\Delta T_{m}$, which is a disturbance variable in the machine part and $\Delta V_{f}$ is a state variable in the excitation system part and a linking variable in the machine part. The outputs of a certain part may be combined, changed into a different form, and converted to be a certain linking input in the other part. As an example for this phenomenon, the output of the algebraic relations and load part: $\Delta \emptyset_{d}, \Delta \emptyset_{q}, \Delta i_{d}$, and $\Delta i_{q}$ are converted into their related electric torque change ( $\Delta T_{e}$ ), which is used as an input linking variable in the machine part and the turbine part.

It is shown in Fig. 1, how the principal of action direction control proposed in this paper is achieved. The transmission line currents flowing to the external grid ( $\Delta i_{d 1}$, $\Delta i_{q 1}$ ) may be an output from the part of the machine algebraic relations and system loading in the normal operation of the system, or they may be inverted to be an input disturbance to the same part in the case of transmission line switching.

An improvement feature of the developed model is that it includes the machine algebraic relations and system loading part as an active/reactive part instead of being considered as passive constants in the system matrix as in Ref. [1].

In the power system model, the generator is modeled by Parks equations ${ }^{[4]}$. Figure 2 shows the IEEE Type 1 excitation system, which is used in this study ${ }^{[7]}$. Block diagram of steam turbine and its governor system ${ }^{[8]}$ is shown in Fig. 3. Figure 4 shows the modelled components of the power system studied.

\section{Solution Technique}

A computer model to simulate the electric power system in the NPP has been developed. This program is based on the solution algorithm described in the flow chart of Fig. 5. In this figure, $A 1, A 2$ and $A 3$ are system submatrices, $B 1, B 2$ and $B 3$ are 


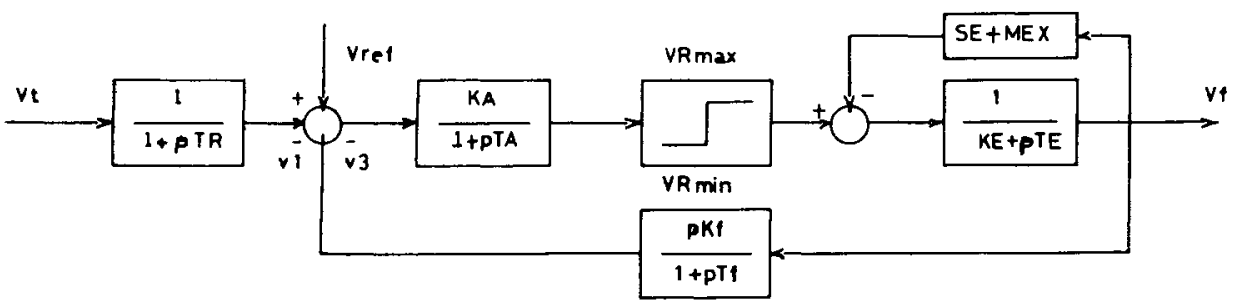

FIG. 2. Excitation system block diagram.

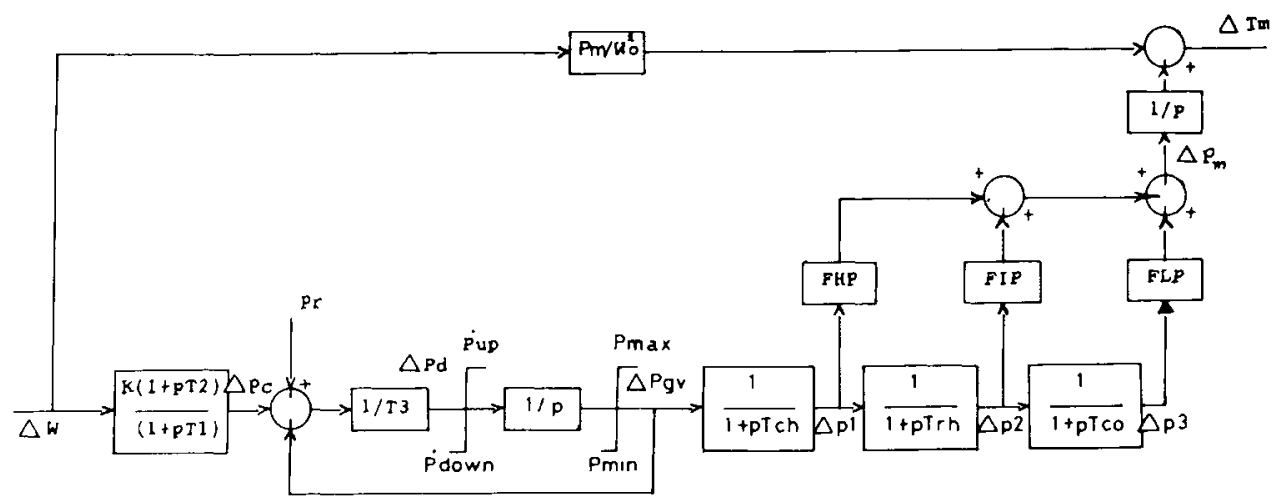

FIG. 3. Block diagram of steam turbine and its governor system.

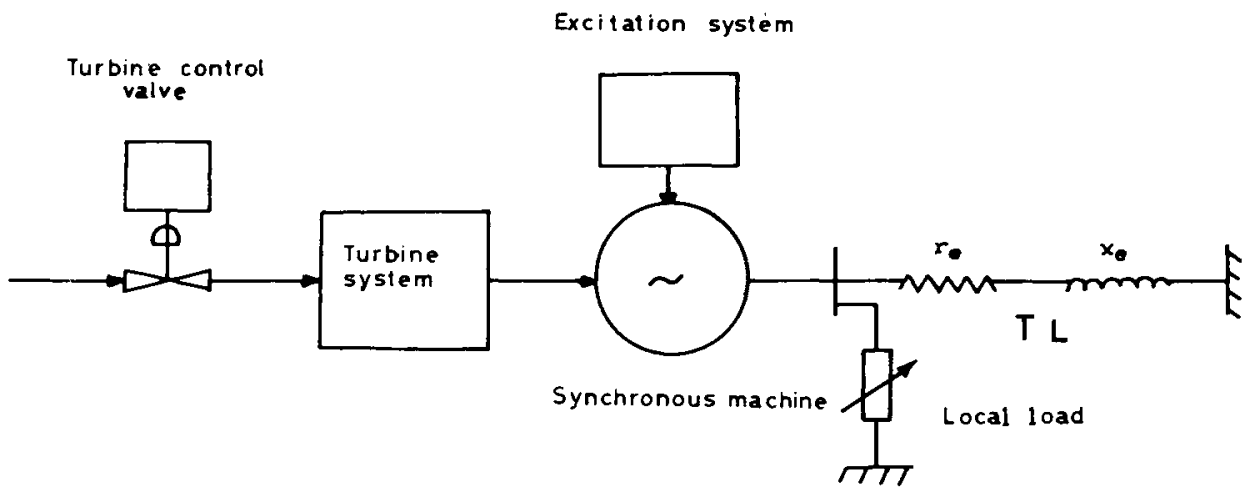

FIG. 4. The modeled components.

input disturbance submatrices, and $C$ and $C 1$ are output matrices. Also dist. stands for disturbance, $T d$ is the time of disturbance, and $T$. L. stands for transmission line. The following are the main steps of this algorithm :

1) Read system data from input data files.

2) Calculate system initial state.

3) Form all matrices required for solving the problem. 
4) Apply disturbances on the system.

5) A check is made to see if the transmission line is switched off, then the system is transferred from the utilized unit operation to the isolated unit operation, or vice versa.

6) The effect of system disturbance is calculated and reflected on different system inputs.

7) The system is integrated to have its response.

8) System response is checked against violation from system operation limits. If there is any violation, system variables are set back to their permissible values, and calculations are repeated.

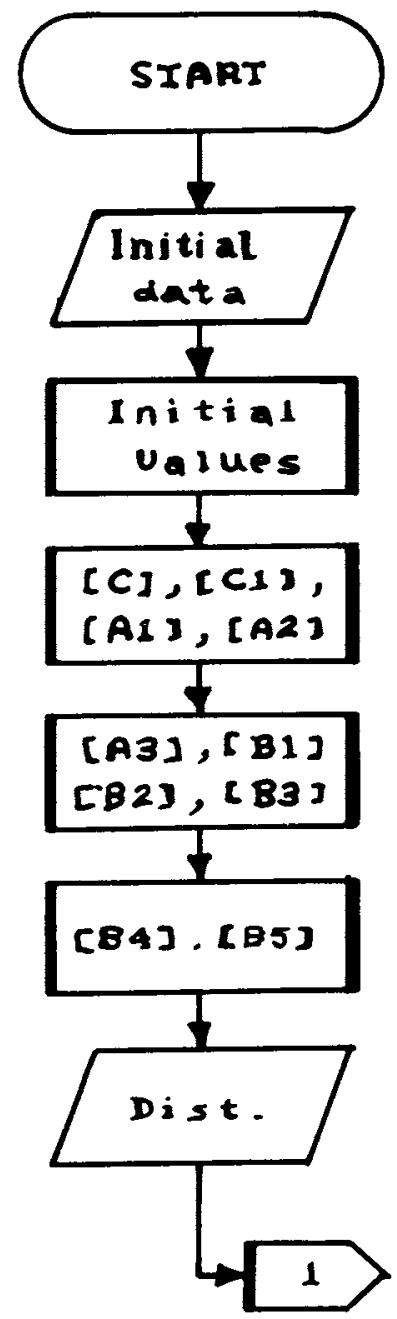

Fig. 5. Flow chart of a synchronous machine connected to an infinite bus and a local load. 


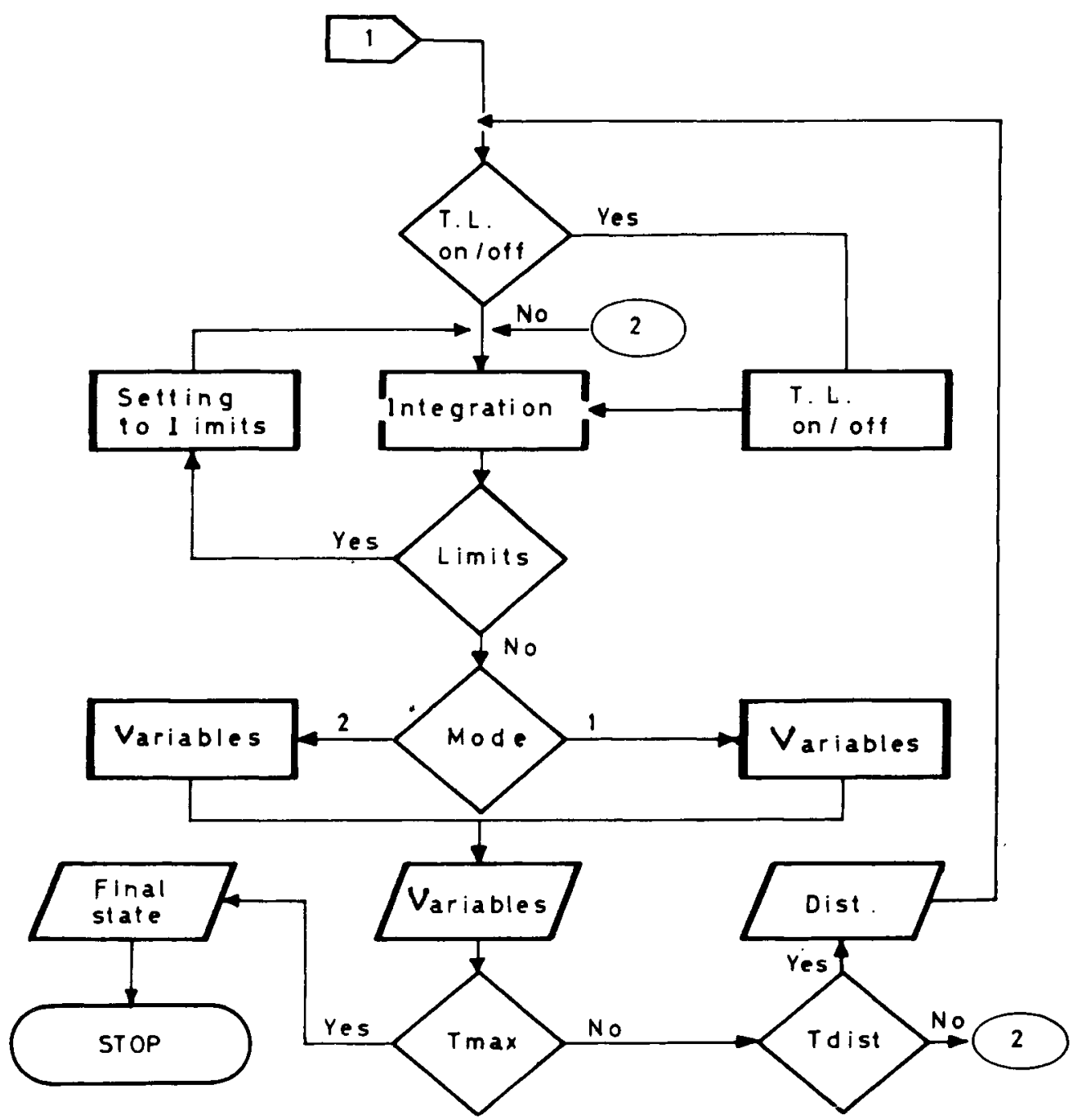

Fig. 5. Contd; Flow chart of a synchronous machine connected to an infinite bus and a local load.

9) System operation mode is checked to correctly choose the type of system variables updating, and system variables are updated to their new values.

10) System response is provided at each time step.

The set of differential equations are solved using the fourth order Runge Kutta method. Solution time step is taken as 0.01 second.

\section{Results and Discussion}

The system considered for digital computation consists of a synchronous generator connected to a local load and to an infinite busbar through a transmission line as shown in Fig. 4. System data are given in per unit in Table 1. 
TABLE 1. System data (per unit).

\begin{tabular}{|c|c|c|}
\hline \multicolumn{3}{|l|}{ Generator } \\
\hline $\begin{aligned} r_{d} & =0.015 \\
x_{q} & =1.620 \\
x_{f d} & =1.6 \\
r_{f} & =0.0081\end{aligned}$ & $\begin{aligned} r_{q} & =0.0135 \\
x_{f} & =0.005 \\
H & =5.3(\mathrm{~s})\end{aligned}$ & $\begin{aligned} x_{d} & =1.700 \\
x_{d}^{\prime} & =0.24 \\
D & =0.005 \quad F=50 \quad(1 / \mathrm{s})\end{aligned}$ \\
\hline \multicolumn{3}{|l|}{ Exciter } \\
\hline $\begin{array}{l}k_{A}=0.05 \\
T_{E}=0.146(\mathrm{~s}) \\
T_{R}=0.027(\mathrm{~s})\end{array}$ & $\begin{array}{l}T_{A}=0.02(\mathrm{~s}) \\
K_{F}=0.057 \\
S_{E}=1.0\end{array}$ & $\begin{aligned} K_{E} & =0.01 \\
T_{z} & =0.45(\mathrm{~s})\end{aligned}$ \\
\hline \multicolumn{3}{|c|}{ Transmission Line } \\
\hline $\begin{array}{l}r_{e}=0.073 \\
\text { Local Load }\end{array}$ & $x_{e}=0.06943$ & \\
\hline$r_{L}=8.072$ & $x_{L}=7.3647$ & \\
\hline \multicolumn{3}{|c|}{ Turbine and Governor } \\
\hline $\begin{array}{l}T_{1}=2.8(\mathrm{~s}) \\
T_{C H}=0.2(\mathrm{~s}) \\
P_{\max }=2.0 \\
F H P=0.3\end{array}$ & $\begin{array}{l}T_{2}=1.0(\mathrm{~s}) \\
T_{R H}=0.8(\mathrm{~s}) \\
\dot{P}_{\max }=0.2 \\
F I P=0.4\end{array}$ & $\begin{aligned} T_{3} & =0.15(\mathrm{~s}) \\
T_{C O} & =0.40(\mathrm{~s}) \\
K & =20.0 \\
F L P & =0.3\end{aligned}$ \\
\hline
\end{tabular}

The response of the shaft mechanical power as a result of the turbine shut down is shown in Fig. 6. It has a decreasing exponential shape of change in a time period of about five seconds. The speed response shown in Fig. 7 has a certain overspeeding in the initial time period after the transmission line disconnection and turbine shut down, this is due to the fast change of electric power with respect to mechanical power that creates a certain accelarating torque on the machine shaft. As a result of this response it is proposed in this paper, in the initial period of time, to connect all the in-house loading - both safety and non-safety loads - to machine terminals to limit the overspeeding in the prescribed period of time. But it is shown that the speed tends to decrease again due to the decrease of mechanical power against the electrical power. Therefore it is suggested that the in-house non-safety loads be switched off from machine terminals when speed regains its initial value, so that the safety loads can benefit mostly of the energy stored in the system inertia for the most achievable time. Results have shown a certain instantanenous overvoltage in the terminal voltage response due to the fast diminishing of the machine current with respect to the machine e.m.f. Therefore, it is suggested here to switch off the in-house loads with the transmission line and to postpone the reconnection of the in-house loads to the machine terminals until the voltage regains its initial value. The delay time of connection is found to be about one second. Figure 8 shows active power $(P$ ) versus time during the recommended operating strategy. 


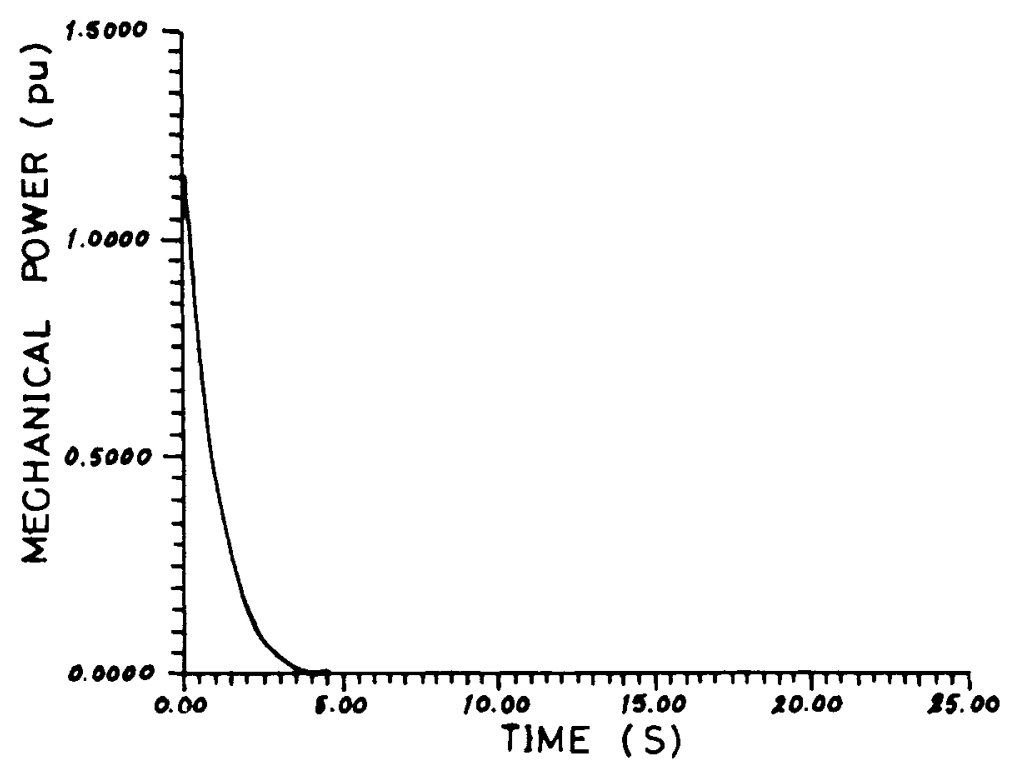

FIG. 6. Mechanical power versus time during the recommended operating strategy.

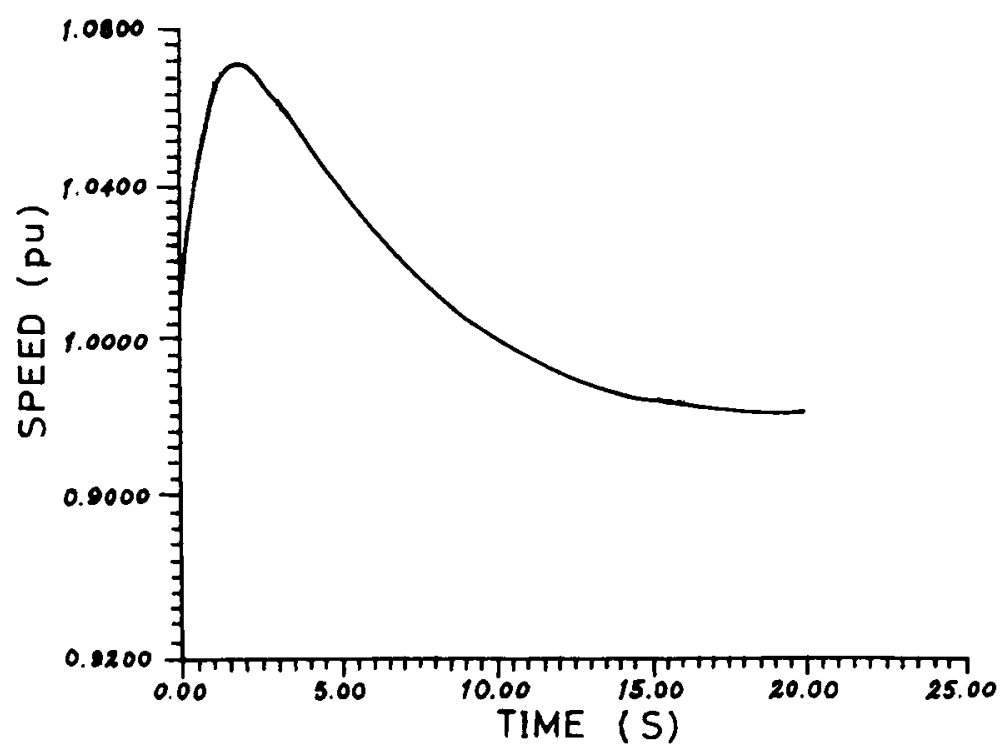

FIG. 7. Speed ( $W$ ) versus time during the recommended operating strategy. 


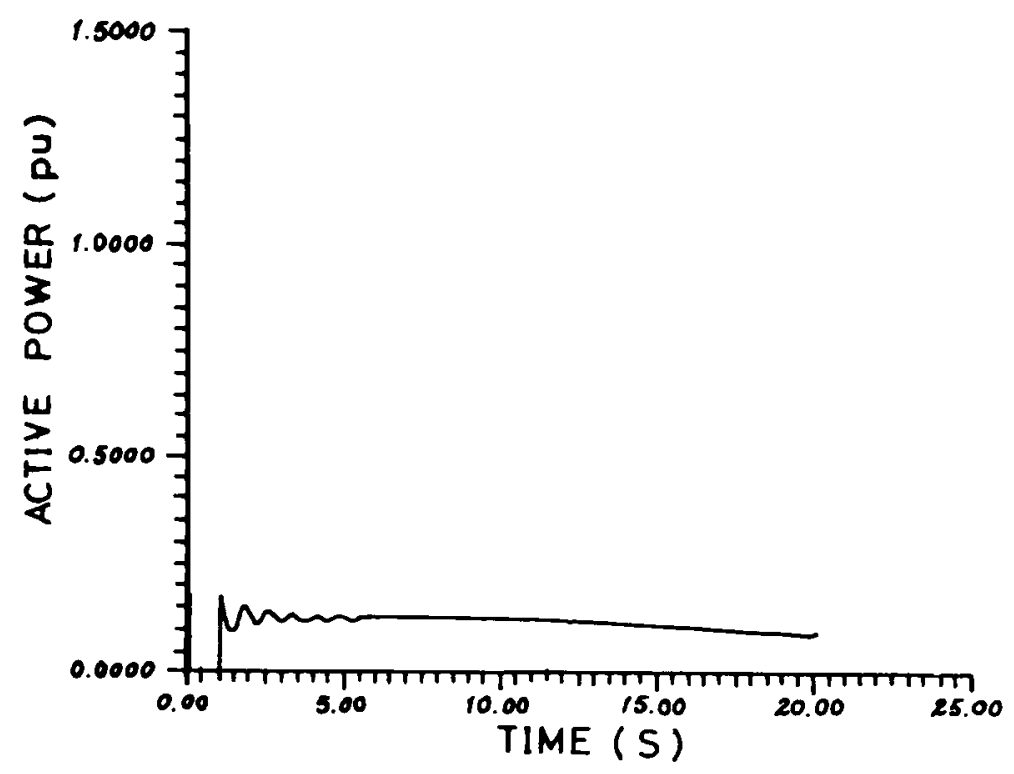

FlG. 8. Active power ( $P$ ) versus time during the recommended operating strategy.

\section{Proposed Operating Strategy}

Based on the above discussion, it is recommended to follow the following operating strategy for the electric power system in NPP.

1) If an accident is sensed with a coincident loss of offsite power, the nuclear reactor is scrammed, the turbine is shut down, and the main circuit breaker is opened disconnecting both the transmission line and local load. Figure 6 shows the shape of change of mechanical power due to turbine shut down.

2) After one second, when the terminal voltage returns back to its nominal value after a certain increase due to machine current fast decrease, all the in-house loads will be connected to the main generator terminals. This is suggested to be made to benefit of power available and to overcome machine overspeeding in the early period of time as a result of total load disconnection from machine terminals as shown in Fig. 7.

3) After ten seconds, when speed goes down to about its nominal value there would be one of two types of operation :

a) If the diesel generator is already started up and is ready to be loaded, the safety loads will be disconnected from the main generator terminals and connected to the diesel generator terminals, according to the unit safety load sequencing design. 
b) If there is any delay in diesel generator start-up, the non-safety loads will be disconnected from the main generator terminals one after another to overcome machine underspeed, and to leave the safety loads in operation for the most available period of time as shown in Fig. 7 \& 8.

\section{Conclusion}

1) The main generator in nuclear power plants (NPP'S) can be added to be a part of the emergency power supply. It could be available to supply the safety loads in NPP'S in the period following the loss of offsite power supply due to an accident condition.

2) The power stored in the turbogenerator inertia is enough to supply power to the safety loads for a period of time up to twenty seconds before emergency diesel generator start-up.

3) It is proposed to connect initially all the in-house loads to the unit generator after the disconnection of transmission line, to benefit of the energy available in the turbogenerator inertia and to limit the shaft overspeeding in the early period of time. When the speed returns back to its nominal value, the non-safety loads will be disconnected one after another, the less important loads will be disconnected first. The safety loads can be supplied with power up to their acceptable underspeed limit.

\section{List of Symbols}

Time constants are in second(s). Other quantities are in per unit on machine base.

$\emptyset_{d} \quad$ direct axis flux linkage.

$\emptyset_{q} \quad$ quadrature axis flux linkage.

$\emptyset_{f} \quad$ field flux.

I armature current.

$i_{d} \quad$ direct axis component of machine current.

$i_{q} \quad$ quadrature axis component of machine current.

$i_{f d} \quad$ field current.

$v_{t} \quad$ terminal voltage.

$v_{d} \quad$ direct axis component of terminal voltage.

$v_{q} \quad$ quadrature axis component of terminal voltage.

$v_{f} \quad$ field voltage.

$v_{f d} \quad$ equivalent field voltage $=v_{f} \times f d / r_{f}$

$r_{p} \quad$ resistance of the equivalent transmission system.

$x_{e} \quad$ reactance of equivalent transmission system.

$\delta$ rotor angle with respect to infinite busbar.

$W \quad$ rotor speed.

$W_{s} \quad$ synchronous speed.

$\Delta W \quad$ speed deviation.

$P_{r} \quad$ mechanical power reference.

$T_{1}, T_{2}, T_{3}$ speed governing time constants, $\mathrm{s}$.

$K \quad$ total effective speed governing system gain.

$\dot{P}_{\text {up }}, \dot{P}_{\text {down }}$ limits on rate of change of power imposed by control valve rate limits.

$P_{\text {max }}, P_{\text {min }}$ power limits imposed by valve travel.

$P_{g v} \quad$ power at valve outlet.

$T_{c h} \quad$ steam chest time constant, s. 


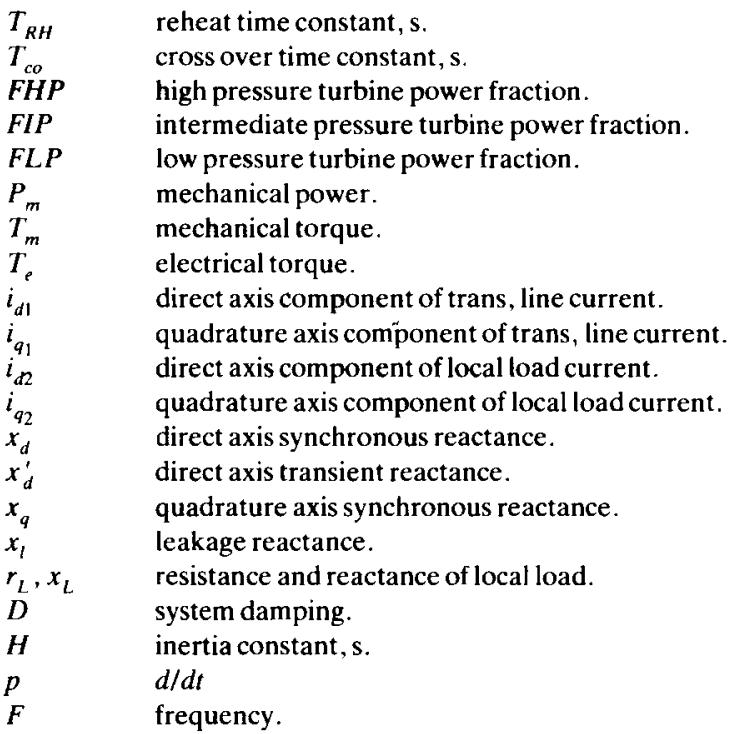

\section{References}

[1] USSR State Committee on the Utilization of Atomic Energy, Report on the Accident at the Chernobyl, Nuclear Power Plant and its Consequences, Information Compiled for the, IAEA Experts Meeting, 25-29 August 1986, Vienna.

[2] International Atomic Energy Agency (IAEA), Safety Guides: Emergency power systems at nuclear power plant, Safety Series No. 50-SG-D7 (1982).

[3] Nuclear Regulatory Commission, Code of Federal Regulations of USA (10 CFR), Part 50, 1978.

[4] Laughton, M.A., Matrix analysis of dynamic stability in synchronous multimachine systems, Proc. IEE, $113(2): 325-336$ (1966).

[5] Barret, P.G., Colot, Y., Herouard, M., Meyer, J.P., Michard, J. and Monville, J.P., Modeling and tests of Fessenhiem Power Station of a 1080 MVA turbogenerator and of its excitation system, IEEE Trans., PAS-100: 3993-4006 (1981).

[6] Ichikawa, T. and Inoue, T., Light water reactor plant modeling for power system dynamics simulation, ibid., Power Systems, Vol. 3(2): 463-471 (1988).

[7] IEEE Committee Report, Computer representation of excitation systems, ibid., PAS-87: 1460-1464 (1968).

[8] IEEE Committee Report, Dynamic models for steam and hydro turbines in power sytem studies, IEEE Trans., PAS-92: 1904-1914 (1973). 


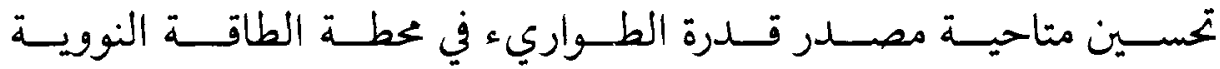

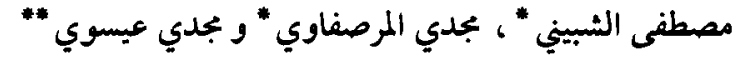

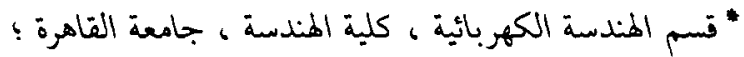

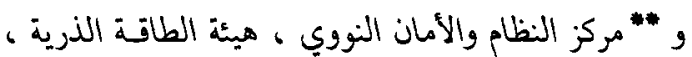

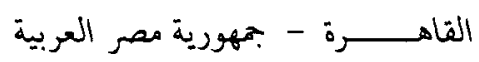

المستخلص . تمت دراسـة تحسـين متاحية مصـدر قدرة الطواريء في عطات الطاقة

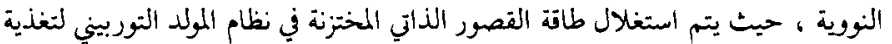

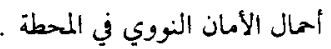

تم عمل نموذج رياضي ويرامج على الحاسب الآلي لتمثيل نظام القوى الكهربائي في

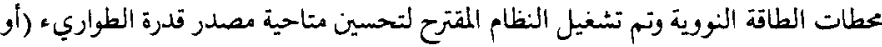

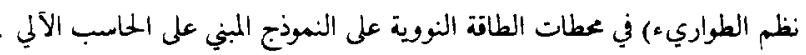

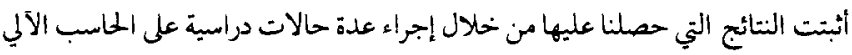

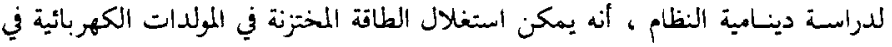

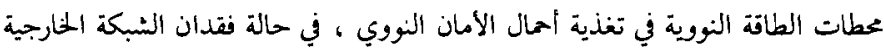

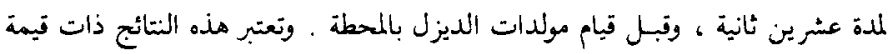

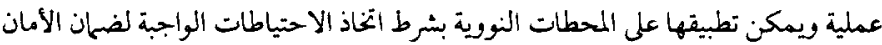

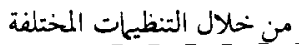

